This is a postprint (final submitted manuscript) version of the following article:

Parris, D., Dapko, J., Arnold, W., \& Arnold, D. (2016). Exploring transparency: A new framework for responsible business management. Management Decision, 54(1), 222-247. https:// doi.org/10.1108/MD-07-2015-0279 


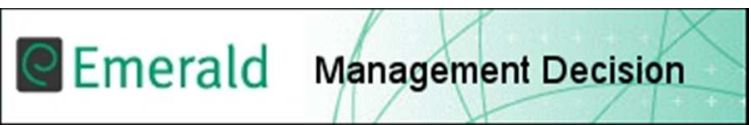

\section{Exploring transparency: A new framework for responsible business management}

\begin{tabular}{|r|l|}
\hline Journal: & Management Decision \\
\hline Manuscript ID & MD-07-2015-0279.R1 \\
\hline Manuscript Type: & Original Article \\
\hline Keywords: & $\begin{array}{l}\text { transparency, systematic literature review, ethical decision making, } \\
\text { Communication, Trust, responsible business management }\end{array}$ \\
\hline \multicolumn{2}{|l}{} \\
\hline
\end{tabular}

\section{SCHOLARONE ${ }^{\text {M }}$ \\ Manuscripts}


Running Head: EXPLORING TRANSPARENCY

\title{
Exploring transparency: A new framework for responsible business management
}

\begin{abstract}
Purpose -The aims of this manuscript are to critically review the relevant literature on transparency, provide a comprehensive definition of transparency, and present a new framework for facilitating the adoption of transparency as an ethical cornerstone and pragmatic strategy for organizational responsible business management.
\end{abstract}

Design/Methodology/approach - A systematic literature review — a methodology adopted from medical sciences to eliminate research bias - was conducted. In doing so, the definitions, antecedents, and consequences of transparency are accessed and synthesized.

Findings -Based upon this process transparency is defined as the extent to which a stakeholder perceives an organization provides learning opportunities about itself. A conceptual framework emerged from the data. It describes when transparency is especially important, what organizations can do to be more transparent, and the potential benefits of transparency.

Practical implications - The transparency framework can be used as a guide for organizations attempting to change their behavior, image, and performance by adopting transparency as a value in their organization. In addition, the framework can be used to create and adopt a universal (i.e., industry-wide or even societal-wide) code of conduct. Furthermore, this review, definition, and framework provide a template for academics to advance transparency theory, and empirically test the construct's application. Originality/value - As a new research field, transparency has lacked a concise definition as well as a conceptual framework. This is the first comprehensive summary of transparency. In addition, this study contributes to the methodology of evaluating construct definitions to advance empirical research.

Keywords Transparency, systematic literature review, ethical decision making, communication, stakeholders, trust, responsible business management.

Paper type General review 


\section{Introduction}

The call for greater organizational transparency has become a mantra chanted by the press, practitioners, and scholars as a promising potential cure to the frequent ethical lapses in business (das Neves and Vaccaro, 2013; Doorey, 2011; Frynas, 2010; Lazarus and McManus, 2006; Makary, 2012; McKay, 2008). The lack of openness with stakeholders has increased skepticism while decreasing trust and confidence that organizations operate within the constraints of social, ethical, and environmental standards (Hein, 2002). In addition, both external and internal stakeholders are becoming even more empowered by advancements in communication technology, thereby making everyone 'always-on, always connected' and creating transparency as a routine expectation (Bennis, Goleman, O'Toole, and Biederman, 2008; Tapscott and Ticoll, 2003). Consequently, more and more stakeholders, i.e., all actors who can be affected by or affect an organization's activities, have become increasingly skeptical, "on guard," and distrustful of firms (Darke and Ritchie, 2007). In an environment in which many stakeholders have become increasingly vigilant against organizations, it is imperative to understand and become more skillful in approaches for reducing skepticism (Darke and Ritchie, 2007). Improving transparency holds promise for being one such solution.

Transparency should serve as a foundational tool for addressing stakeholder distrust and improving responsible management practices of organizations. Ethical behaviors are commonly evaluated in terms of assessments of "right" or "just" standards of behavior between parties in a situation (Ferrell and Gresham, 1985). These ethical judgments are made based on what one believes is fair and acceptable in terms of cultural, familial, and individual standards (Reidenbach and Robin, 1990; Reidenbach, Robin, and Dawson, 1991). An ethical assessment is 
person- and context-specific and dependent on one's cultural, professional, industry, organizational, and personal characteristics (Hunt and Vitell, 2006).

An organization's selection and implementation of core values communicates multiple messages to all stakeholders, including who the organization is, how to act within the organization, and how to engage with organizations and people outside of the organization. If values are successfully implemented and communicated, ethical direction is provided to all operational facets of the firm (AMA, 2010; Robin and Reidenbach, 1987; WOMMA, 2010). It is posited that an organization should be able to improve relations and outcomes for all of its stakeholders if the organization embraces transparency as a core value and embeds it into its culture, operating procedures, and style of communication.

Before examining the mechanisms, outcomes, and impacts of transparency as a core responsible management practice embraced throughout the organization, transparency must be defined. Despite transparency becoming something of a buzzword in business, the literature shows that definitions of transparency vary widely, have very little consistency, and are typically imprecise (Baker, 2008; Bird and Wang, 2011; Cornand and Heinemann, 2008; Eggert and Helm, 2003; Hofstede, 2003; Hultman and Axelsson, 2007; Jahansoozi, 2006; Vaccaro, 2012; Vaccaro and Sison, 2011; Warren, Burns, and Thacket, 2012). Imprecise definitions lead to poor measurement, low construct validity, and incorrectly identifying relationships (MacKenzie, 2003). It is vital to understand exactly what "transparency" means if organizations are to adopt it as a responsible management practice.

The numerous ethical lapses in business indicate many organizations operate with norms that foster opacity rather than transparency. The integrity of organizations' communications with stakeholders has been repeatedly blemished by various opaque strategies, to the point that there 
are now terms for a variety of ways organizations miscommunicate, such as greenwashing, bluewashing, and whitewashing (Laufer, 2003; Tellings, 2006). Even in closely-knit supplierbuyer relationships, a lack of transparency can lead to dysfunctional relationships that result in moral dilemmas (Roloff and Aßländer, 2010).

Transparency has been touted as the ideal solution for reducing corruption and stakeholder distrust by bringing issues into the open that are usually left in the dark (Halter and de Arruda, 2009; Misangyi, Weaver, and Elms, 2008). To date, organizations' efforts to increase transparency have often simply been a reactionary strategy for managing organizational and individual reputations during public scandals (Cutler, 2008; Holusha, 1989; Klara, 2010). As a consequence, some firms have adopted ethical codes of conduct, which have significantly improved business professionals' ethical decision making (McKinney, Emerson, and Neubert, 2010). A sound definition of "transparency" is imperative for gaining greater insight into a myriad of transparency-related issues, along with helping enhance theory and practical applications.

Consequently, the aims of this manuscript are to critically review the relevant literature on transparency, provide a comprehensive definition of transparency, and present a new framework for facilitating the adoption of transparency as an ethical cornerstone and pragmatic strategy for organizations. An inductive process was employed to identify transparency frameworks, which provided a qualitative analysis that helped identify key relationships and factors of transparency. This qualitative analysis generated the first comprehensive summary (e.g., systematic literature review) of transparency. The research questions explored were: how is transparency defined, what are the antecedents of transparency, and what are the consequences of transparency? Next, a succinct definition of transparency was developed from evaluating the 
quality of definitions and the main themes provided in the literature. Lastly, this process led to the development of a conceptual framework for transparency.

\section{Transparency and trust}

Trust is an antecedent and consequence of transparency. Transparency is necessary to create a sense of trustworthiness and accountability. Trust implies that one is willing to assume the risk that goes along with taking action based on the reliance of another (Stanley, Meyer, and Topolnytsky, 2005). Constituents can build trust in an organization based on perceived organizational transparency by the organization sharing information, creating learning opportunities, and communicating openly. Palanski et al. (2011) illustrate that one will be more willing to be transparent when there is trust that others will not abuse the power gained from increased knowledge. An organization must trust its constituents to share information.

Transparency implies that organizations will go the "extra mile" to ensure stakeholders are well-informed (by providing relevant, effortless learning opportunities), and research suggests that an organization's extra effort is rewarded. Transparency has the potential to benefit an organization's employees, customers and partners, as well as entire societies. Trust is the primary benefit accruing to transparent organizations. Trust is confidence in an exchange partner's reliability and integrity (Ahearne, Jelinek, and Jones, 2007; Eisingerich and Bell, 2008; Urban, Amyx, and Lorenzon, 2009; Yim, Tse, and Chan, 2008). Trust is discussed as a benefit of transparency between leaders and followers (Vogelgesang and Lester, 2009), an organization and its customers (Beulens, et al., 2005; Chua, Robertson, Parackal, and Deans, 2012; Jahansoozi, 2006), and government institutions and its constituents (Halachmi and Greiling, 2013). Furthermore, transparency within and between individuals, teams, and companies systemically 
affects overall levels of trust within a society at large (Blomgren and Sundén, 2008; Brown and Michael, 2002).

Like transparency, trust can be understood by exploring its causes, nature, and effects. To date, the most widely cited models of trust was developed by Mayer and Schoorman (1995) and extended by Schoorman, Mayer, and Davis (2007). Mayer and Schoorman (1995) focused on the interpersonal nature of trust; Schoorman, Mayer, and Davis (2007) acknowledged that they had originally intended to extend their theory to corporate trust, including stakeholder trust and corporation to corporation trust. They proposed a model in which perceptions of trustworthiness and propensity to trust contribute to a person's willingness to take risks, or willingness to be vulnerable, with the other party. The willingness to be vulnerable is predicated on the individual's basic cost/benefit analysis; if the perceived potential benefits of risk taking outweigh the perceived potential costs of being vulnerable, then the individual will be more willing to take a risk in that relationship.

According to Mayer and Schoorman (1995) and Schoorman, Mayer, and Davis (2007), an individual, or corporation, is perceived as trustworthy based on favorable evaluations along three dimensions: ability, benevolence, and integrity. Mayer and Schoorman write, "Ability is that group of skills, competencies, and characteristics that enable a party to have influence within some specific domain" (p. 717). Ability is analogous to competence and expertise. Benevolence is defined as "the extent to which a trustee is believed to want to do good to the trustor, aside from the egocentric profit motive" (p. 718). Benevolence is perceived as akin to altruism and loyalty. Integrity "involves the trustor's perception that the trustee adheres to a set of principles that the trustor finds acceptable" (p. 719). If an individual has a low propensity to trust and perceives another individual as lacking ability, benevolence, or integrity, then a trusting 
relationship is highly unlikely. They also propose that early in a relationship the most important factor in establishing trust is to demonstrate integrity through transparency. Mayer and Schoorman (1995) and Schoorman, Mayer, and Davis (2007) conclude the trust is ultimately defined by an individual's willingness to be vulnerable to another party, which involves taking risks in the relationships.

It is proposed that transparency serves as an antecedent to stakeholder trust. In light of the foregoing discussion, however, transparency alone is not sufficient. Willingness for an organization to share information about itself is necessary but insufficient to trust development. Imagine a new company attempting to sell a new service. The ability questions, the dimension of trust, on any consumer's or investor's mind include: 'can this person or company deliver on the services promised; do they have the expertise; do they have the scale necessary to succeed?' If the answer to these questions is negative, then consumers as well as investors will be unwilling to take a risk by buying from or investing in that company. Benevolence and integrity questions, dimensions of trust, function the same way as when a stakeholder asks the following questions: 'is this person/company interested in my welfare or are they willing to sell me inferior products at inflated rates in order to increase their profits?' For instance, if a company's mission statement only mentions maximizing investor return, then a consumer may be uninterested in purchasing from that company because they are concerned about that company's benevolence. If a buyer has heard through contacts that a supplier is inconsistent in delivering product in a timely manner then that buyer may call into question that supplier's integrity and, unless that buyer has a very high propensity to trust, will be unlikely to risk signing a supply contract.

It is proposed that transparency is most relevant along the three trust factors in the following order: ability, benevolence, and integrity. Trust and distrust are viewed as mutually 
exclusive. Distrust is conceived as the absence of trust (Schoorman, Mayer, and Davis, 2007). Evaluating the communication of a company as an investor, one is most likely to first consider whether or not the company has the ability to deliver on its promised goods or services. If the investor judges that the company does not have the ability, that the potential risk of financial loss outweighs the potential return on investment, then the investor will place his or her trust and, therefore, investment elsewhere. Simply stated, lack of trust in ability is a nonstarter for internal and external constituents alike. In this instance the investor is said to distrust the organization's ability to perform.

Distrust might also be based on perceptions of an organization's benevolence. If employees perceive that the primary purpose of the management team is to exploit them, then distrust will ensue. Employees may believe that the management team has the ability to treat them fairly, but trust will likely break down if employees do not perceive managers as benevolent. The same holds true for consumers as well. If consumers perceive a company as having the ability to make a quality product based on previous performance, but that company begins producing the same product with cheaper materials and markets the inferior product at the same or greater purchase price, consumers may very well call into question that company's benevolence and, as a result, distrust is more likely to develop. Such a violation of trust will likely have long term negative impact on that company's financial performance.

Trust might also be threatened by perceived value incongruence, or perceptions of integrity. Again, according to Mayer and Schoorman (1995), an organization is perceived to have integrity, an essential component of trustworthiness, when it is perceived by constituents to adhere to an acceptable set of (ethical) principles. Notice that the company does not have to be 
perceived as unethical for the constituent to perceive that company lacks integrity. The company and constituent might have ethically or morally equivalent, yet incongruent principles.

For many organizational constituents an important ethical and moral commitment is to the triple bottom line: people, planet, and profit. For many, social responsibility and ecological sustainability, in addition to profitability, are core ethical principles by which an organization will be evaluated as to whether or not they are engaging in responsible business management. Failure to engage in responsible business practices will likely lead to constituent perceptions of untrustworthiness. Furthermore, the perception that an organization fails to engage in responsible business practices will have an equally deleterious effect. Thus, further bolstering the necessity of transparency. We may be approaching a business climate in which an organization that fails to explicitly address each of these three areas will be assumed to lack integrity and, therefore, will be perceived as untrustworthy. We propose that transparency, especially regarding the triple bottom line and responsible business management practices, is the cornerstone of employee engagement, customer loyalty, organizational performance, and societal and ecological sustainability.

\section{Benefits of transparency}

As a responsible business management practice transparency can positively benefit employees, customers and partners, the organization, and society.

\subsection{Employee benefits}

Internally transparent organizations are open to sharing information within and across departments and teams, and from both top down and bottom up. An open culture of internal knowledge sharing results in employees being more engaged in their job role and higher performance (Vogelgesang and Lester, 2009). Employee engagement is enhanced because 
employees have a better understanding of how their role fits into the strategic direction of the organization, and they tend to trust management more (Vogelgesang and Lester, 2009). This trust due to transparency helps employees make better decisions in accordance with the strategic direction of the firm (Street and Meister, 2004). Transparency literature supports the Tenbrunsel and Smith-Crowe ethical decision making framework (2008), which contends that employees are aware of transparency issues and are both givers and receivers of transparency who are more responsible in their decision making (Halter, de Arruda, and Halter, 2009), less likely to act opportunistically (Bessire, 2005), and more cooperative during acquisitions and mergers (Piske, 2002). Transparency experienced by internal stakeholders has a potentially profound impact of shifting organizations toward higher levels of transparency experienced by external stakeholders.

\subsection{Customers and partners benefits}

Externally transparent organizations are open to sharing information with stakeholders, such as their current and prospective customers, supply chain members, investors, and partners. An organization's brand, perceived transparent or not, "is derived from what institutions have done and not what they would ideally do (what has been termed the "promise/performance gap")" (Bernstein, 2009, p. 604). Organizations that are transparent with their external stakeholders benefit from customers who have more favorable attitudes toward the brand (Arens, Deimel, and Theuvsen, 2011), perceive the firm as more credible (Brown and Michael, 2002), perceive greater price fairness and procedural justice (Carter and Curry, 2010; Miao and Mattila, 2007), have greater customer satisfaction (Eggert and Helm, 2003), perceive greater value of the firm's products (Carter and Curry, 2010; Eggert and Helm, 2003), trust the organization more (Beulens, et al., 2005; Jahansoozi, 2006), and ultimately have a greater purchase intention (Bhaduri and Ha-Brookshire, 2011). Transparency with supply chain members results in greater supply chain 
efficiencies in flow of materials (Hultman and Axelsson, 2007), cooperation (Beulens, et al., 2005) and trust (Beulens, et al., 2005). Employees, customers, and business partners trusting a firm due to its transparency efforts may enable the firm to outperform its competitors.

\subsection{Organizational benefits}

Organizations that are internally and externally transparent are said to have a greater competitive advantage (Halter and de Arruda, 2009; Vogelgesang and Lester, 2009). Transparency enhances organization-wide understanding of the competition (Halter and de Arruda, 2009), which allows organizations to improve differentiation of their product offerings to targeted consumers (Carter and Curry, 2010). This benefit is further facilitated by greater collaboration and cooperation with stakeholders (Jahansoozi, 2006). Transparent organizations are also generally more committed to stakeholders compared to nontransparent organizations, thereby leading to healthier stakeholder relationships (Jahansoozi, 2006) and overall better business practices (Halter and de Arruda, 2009; Halter, et al., 2009). Firms' transparency efforts drive less haphazard decision making (Granados and Gupta, 2013), and more ethically sound (Halter and de Arruda, 2009) and socially responsible (Awaysheh and Klassen, 2010) decision making. For example, firms that have a marketing transparency decision-making framework choose to manufacture safer products (Beulens, et al., 2005). A marketing transparency decision-making framework creates an atmosphere where sharing detailed information is the norm (Bansal and Kistruck, 2006), and engaging in undetectable deceptive marketing actions is difficult to hide (Warren, et al., 2012). Ultimately, this transparency leads to a more favorable brand image (Halter, et al., 2009) and greater marketing message persuasiveness (Miao and Mattila, 2007). Transparency between organizations and its customers is a technique to strengthen the relationships (Gupta, Grant, and 
Melewar, 2008). Most importantly, these benefits lead to increased sales and greater profit margins (Carter and Curry, 2010).

\subsection{Societal benefits}

Today's stakeholders evaluate organizations by more than just its sales and profits. The "triple bottom line" concept has become increasingly popular to help stakeholders compare and assess organizations from a broader viewpoint incorporating economic, ecological, and social impacts. Transparency is said to be a key driver for many organizations that have adopted the triple bottom line agenda into its communication strategies and reporting metrics (Elkington, 1998, 2004). Society as a whole benefits when organizations engage in transparent practices (e.g. adopting the triple bottom line approach). When transparent organizations provide relevant and easy learning opportunities to stakeholders it is easier to see untruths that previously would have been remained hidden. Transparency leads to greater consumer education (Vaccaro and Sison, 2011) and thus a more equitable balance of power between the organization and its stakeholders (Cheng, 2011). Transparent organizations are less able to exploit societal resources (Vaccaro and Sison, 2011), skew reality in their favor and falsify outcomes (Halachmi and Greiling, 2013; Hood, 2007), hide agendas and keep secrets (Jahansoozi, 2006), and engage in deceptive and corrupt practices. Transparency implies that stakeholders have the ability to hold organizations accountable (Halachmi and Greiling, 2013; Jahansoozi, 2006; Ross, Gross, and Krumholz, 2012; Stasavage, 2004; Vaccaro and Sison, 2011) by verifying the organization's behaviors (Campbell, 2007; Halter and de Arruda, 2009). If transparency efforts enhance intra-organizational ethical decision making and triple bottom line performance then organizations would be wise to adopt a transparency framework. 


\subsection{What transparency is: Bringing together causes and outcomes}

An organization's awareness of transparency plays a critical first step in acting as a framework for decision making. Organizations, however, may resist greater transparency for a variety legitimate as well as illegitimate reasons including hiding unethical or illegal behavior, impression management, lack of awareness, lack of trust of internal or external stakeholders, fear of public reaction, maintain competitive advantage, and due process for internal affairs investigations, and the like. People in organizations likely resist greater transparency for the same or similar reasons any organizational change effort is resisted. For example, individuals may fear the disruption of interpersonal connections at work, loss of control, loss of routine, or the perception of a threat to job security, and, thus, be more likely to resist change in general and greater transparency in particular (Marci, Tagliaventi, and Bertolotti, 2002). However, there appears to be a gap in the literature as to the causes related to resistance specifically to greater transparency such that more research is warranted to determine whether or not the same mechanisms that lead individuals and organizations to resist change generally also lead individuals and organizations to resist transparency-related change specifically. Nevertheless, once transparency becomes salient and activated as a core organization value, it can and should be used as a dominant guideline or theme. To help fill the gap in literature and practice and develop a useful transparency framework for decision makers, the first step was systematically exploring transparency definitions, followed by examining the precursors and outcomes of transparency.

\section{Methodology}

In order to align with the central theme of transparency, and to help mitigate bias, a systematic literature review was conducted. The systematic literature review focused on exploring peer reviewed articles that examined transparency as the central theme of the paper and in organizational contexts. The approach of this review included extensive database searches with the intention of confirming, as much as possible, that all transparency literature was identified, 
while maintaining the focus on literature of greatest relevance to the research questions (e.g., conceptual or empirical studies that investigated transparency in organizational contexts). By utilizing this methodology adopted from the medical field, the literature searches are objective, replicable, and comprehensive (Parris and Welty Peachey, 2013; Weed, 2005). Articles were selected based on the predetermined inclusion and exclusion criteria described below, and then assessed and synthesized based on the specific research questions (Klassen, Jadad, and Moher, 1998; Parris and Welty Peachey, 2013).

\subsection{Search methods}

Published studies were identified through a search of electronic databases accessible through the authors' institution. Databases included in this review were Academic Search Complete, Business Source Complete, Social Science Journals, Communication and Mass Media Complete, PsycINFO, ProQuest Research Library (Business), ERIC, and ABI/INFORM. The searches were conducted in a systemic manner, in the order listed above.

\subsection{Inclusion and exclusion criteria}

The initial search required that articles retrieved in the review must: (a) be published in a peerreviewed journal; (b) be written in English language; and, (c) use the word "transparency" as a keyword or in the abstract. There was no restriction on publication date or journal. The number of internal duplicates and external duplicates was tracked. Duplicated articles from the last database searched were deleted, while new articles were kept. The search resulted in a pool of 537 articles.

A further refinement was needed to ensure that all 537 articles were relevant for the analysis. The refinement process included five steps. In step one, each article's abstract was read in full and its content scanned to ensure the article not only met the previously listed specified 
search criteria, but also included "transparency" as a major topic of discussion. Articles that met the criteria were labels as "in" for further review, and those that did not meet the criteria were labeled "out" and removed from any further consideration.

Step two included further refinement of the "in" articles for appropriateness by two judges based on the search criteria. To remain in the pool, the article type had to be either a conceptual or empirical study (thus not an essay, book review, editorial, literature review, opinion paper, or journalistic/anecdotal article), with a main focus of discussing transparency in terms of theory, model development, or case analysis. Two judges read each article thoroughly and independently, with a particular focus on the extent to which transparency was discussed in the article. Each article was coded as "in" or "out" based on the specified criteria, with questionable articles designated as "maybe." Coding articles as "maybe" avoided removing them from the consideration set too early in the process; they were set aside for further discussion. Steps three, four, and five followed the same refinement process, resulting in a final sample set of 46 peer-reviewed articles.

\subsection{Sample}

The 46 peer-reviewed articles generated from the five-step process outlined above were published between 2002 and 2013. This final pool contained 25 conceptual articles, 18 qualitative articles and 3 quantitative articles, published across 35 journals. The articles represent three primary functional areas: marketing, organizational behavior, and political science; there were 20 marketing articles (43\%), 16 organizational behavior articles (35\%), and 10 political science articles (22\%). The marketing articles referred to transparency in the contexts of marketing communications $(n=10)$, supply chain $(n=5)$, pricing $(n=4)$, and marketing strategy $(n=1)$. The organizational behavior articles referred to transparency in the contexts of strategic 
management $(n=6)$, leadership $(n=4)$, corporate governance $(n=3)$, work teams and team dynamics $(n=2)$, and negotiations $(n=1)$. The political science articles addressed transparency in the contexts of politics $(n=4)$, management of public programs $(n=3)$, government policies $(n=2)$, and healthcare $(n=1)$.

\subsection{Data analysis}

Data from the sample of 46 articles was abstracted and documented using the matrix method (Garrard, 1999). In this analysis, the following information was abstracted from each article: article type (conceptual, quantitative, or qualitative), transparency definition, transparency measures, proposed antecedents, and proposed consequences. Lastly, a definition evaluation classification was developed to evaluate the transparency definitions relative to quality of definition. Based upon synthesis and analysis of the measurement literature (Churchill, 1979; MacKenzie, 2003; MacKenzie, Podsakoff, and Podsakoff, 2011; Mowen and Voss, 2008; Rossiter, 2002; Schwab, 1980) five criteria were identified to evaluate construct definitions. Table 1 describes the quality definition evaluation criteria, which was based on the measurement literature.

Insert Table 1 about here

For this study, the transparency definitions in each article were evaluated using the definition evaluation classification. Overall, nine of the 46 articles did not provide a transparency definition and three other articles adapted definitions currently in the literature. These articles were removed from the analysis due to a lack of definition or to avoid duplication. If articles provided 
multiple definitions or descriptions of transparency, the first original description or definition was analyzed.

In total, 34 definitions were assessed by two independent judges along the five stated criteria. In order to ensure that the content analysis for the transparency definitions was reliable, valid, and objective (Kolbe and Burnett, 1991), the proportional reduction in loss (PRL) reliability measure was calculated (Rust and Cooil, 1994). The PRL reliability is a "direct extension and generalization of Cronbach's alpha to the qualitative case" (Rust and Cooil, 1994, p. 9). The PRL reliability measure was calculated by dividing the total number of pair-wise agreements $(n=120)$ between the two judges by the total number of potential pair-wise agreements $(n=170)$ for a total percentage of agreements $(71 \%)$. The pair-wise percentage of agreements of $71 \%$ corresponds to a PRL reliability of .80 indicating the inter-rater reliability was adequate.

\section{Findings}

The SLR highlights that transparency is being examined in the areas of marketing, organizational behavior, and political science. To date, the majority of research on transparency is largely exploratory in nature, with articles being either conceptual $(n=25)$ or qualitative $(n=18)$. Only three quantitative articles were discovered. As scholars seek to understand transparency as a distinct field of study, they are publishing across a variety of journals $(n=35)$, which supports the widespread application of transparency. The following discussion is organized around the research questions.

\subsection{How is transparency defined?}

In the sample of 46 articles, the majority discuss transparency in terms of an organization's “openness" relative to sharing information. While not all authors explicitly used the terms 
“open” or "openness," the meaning was generally implied. For example, transparency is conceptualized as:

- Openly and freely sharing information (Baker, 2008; Hofstede, 2003; Vaccaro, 2012; Vaccaro and Sison, 2011)

- An ability of consumers to see through a deception (Warren, Burns, and Tackett, 2012)

- Understanding an other's intentions and goals (Cornand and Heinemann, 2008)

- Openness within organizations (Bird and Wang, 2011; Jahansoozi, 2006)

- Sharing what is not usually shared (Eggert and Helm, 2003; Hultman and Axelsson, 2007)

- Being informed (Eggert and Helm, 2003)

- Having a shared understanding (Beulens, Broens, Folstar, and Hofstede, 2005; Hofstede, 2003)

- Being open to giving and receiving feedback (Vogelgesang and Lester, 2009)

- Being forthright, especially regarding motives and reasons behind decisions (Drew, Nyerges, and Leschine, 2004; Pirson and Malhotra, 2008; Vogelgesang and Lester, 2009)

- Freely volunteering information (Baker, 2008)

Overall, the literature is inconsistent in providing a high quality definition, which is necessary for this expanding field to be solidly grounded and moved forward. Specifically, transparency as a construct is often misrepresented in literature via imprecise and ambiguous language or by defining the construct in terms of its antecedents and consequences, which can lead to measurement problems. For example, in applying the quality definition criteria (see Table 1), judges rated the definition "transparency is strongly related to information" (Bessire, 2005, p. 
429) as low quality because it lacks specificity in terms of what is being measured and to whom or what the construct applies.

High quality construct definitions must possess measurement, attribute, and entity specificity, along with conceptual precision and overall clarity (Parris and Welty Peachey, 2013). This definition clearly lacks the precision necessary to construct valid and reliable scale items. Moreover, the phrase "related to" implies that it is being defined by a correlate - either an antecedent or consequence. Most definitions in the sample were classified as either low quality $(n=25)$ or medium quality $(n=7)$, with similar justifications as noted above.

Surprisingly, only two of the 34 definitions met all five of the high quality construct definition criteria.. For these two definitions, the judges had a clear idea of the construct's domain, what was being measured, and who or what the construct was about. Even these high quality construct definitions, however, are not sufficient for moving the transparency domain forward.

Interestingly, both of the high quality definitions conceptualize transparency differently than all other articles. Whereas all other articles define transparency relative to being open, providing learning opportunities, and sharing information with others, these two articles define transparency relative to internal traits or abilities. This is easily seen in this definition: "transparency is the ability of consumers to see through a deception" (Warren et al., 2012, p.123). The primary focus of this definition is that transparency refers to a consumer's trait characteristic (ability to detect deception), rather than a firm's trait characteristic (openness). Logical measurement items for this definition might include various derivations of "I am able to detect when someone is lying to me." Clearly, while this measurement item reflects the construct 
definition, it does not adequately and directly represent the key transparency themes of "openness" and "sharing of information" from the organization's perspective.

The second high quality definition is akin to the first. The definition is "transparency is the tendency for individuals to overestimate the extent to which their internal states and intentions are apparent to an outside observer" (Garcia: 2002, p. 133), which also reflects a trait characteristic of oneself rather than an organization. One judge also noted, "this definition measures 'illusion of transparency,' an intrinsic characteristic," thereby further differentiating it from the rest.

The literature simply does not contain a clear and concise conceptualization of transparency. Furthermore, the existing definitions neither optimize the balance of specificity and broadness needed to apply to the entire organization, nor do they address the theme of “openness" represented throughout the literature.

\subsection{How should transparency be defined?}

Based on the synthesis and assessment of the sample and employing the quality definition classification as a guide, the following definition of transparency is offered:

\section{The extent to which a stakeholder perceives an organization provides learning} opportunities about itself.

Unlike the majority of previous definitions (Baker, 2008; Bird and Wang, 2011; Cornand and Heinemann, 2008; Eggert and Helm, 2003; Hofstede, 2003; Hultman and Axelsson, 2007; Jahansoozi, 2006; Vaccaro, 2012; Vaccaro and Sison, 2011; Warren, Burns, and Thacket, 2012), this definition has object of measurement specificity, object attribute specificity, entity specificity, conceptualization precision, and overall improved clarity over the existing definitions. See Table 1 for criteria explanations and a more detailed review regarding how this 
definition meets the quality standards. The definition provides a fundamental conceptual foundation from which both academics and practitioners can advance transparency theory, and empirically explore its antecedents and consequences.

This new transparency definition conceptualizes transparency in terms of stakeholder perceptions. Stakeholders most likely form perceptions of transparency during some communication interaction with a firm. A communication interaction is defined as a communication event in which information is shared between a firm and a stakeholder. The interaction can be between a stakeholder and any of a firm's boundary spanning employees or boundary spanning systems. Boundary spanning employees include salespeople, customer service representatives, and human resources personnel, whereas boundary spanning systems include a firm's website, automated phone messages, and email marketing messages.

There are numerous examples of both stakeholder-initiated and firm-initiated communication interactions. With regard to stakeholder-initiated interactions, a stakeholder may seek or request information from one of an organization's boundary spanners or systems. For example, a stakeholder may seek or request information from a salesperson while shopping in a store, from a customer service representative over the phone, or by surfing the organization's website. Information sought may relate to the organization's products or to the firm's legal, ethical, and operating practices.

Relative to the firm's products, a stakeholder may want to know specific features, advantages, or benefits of a particular product. With regard to the organization's legal, ethical, and operating practices, a stakeholder may want to know from which country materials are sourced for a particular product, the manufacturing processes of and human labor conditions for the product, or to understand the business wealth and health of an organization. Relative to firm- 
initiated communication interactions, a firm may contact a stakeholder with product updates, special promotions, and corporate happenings and may do so by various means such as email, phone, text messaging, and mail. Providing information opportunities for the consumer such as maintaining a corporate website, distributing news releases, or hosting product information seminars or manufacturing plant tours, are also examples of a firm initiating communication interactions. Each communication interaction has the potential to improve stakeholder perceptions of organization transparency.

\subsection{How can transparency be improved?}

If transparency relates to being open by providing learning opportunities to stakeholders, then what can organizations do to increase transparency? The literature suggests two key antecedents that drive stakeholder perceptions of organization transparency. First, organizations should provide relevant information to stakeholders. Second, organizations should share information in such a way as to make learning easy for stakeholders.

An organization should have relevant information to increase perceptions of organization transparency. A common theme is that information should be sufficiently relevant to the audience to enable their decision making. When a firm discloses information about itself to stakeholders, it sends a "signal" of transparency (DeKinder and Kohli, 2008). However, one caveat is that the information must be perceived as valuable to stakeholders, and thus relevant. The Global Reporting Initiative (GRI), a nonprofit organization that helps organizations become more transparent with regard to reporting, links information relevance to transparency and suggests that information reported by organizations should be useful, understandable, and sufficient (GRI, 2006) in order for stakeholders to make informed decisions. 
"Relevant" means different things in different contexts. For example, in accounting and finance, transparency refers to companies sharing information about past financial performance, future forecasts, and current operations (Nielsen, 2004, 2005). Whereas, in marketing, transparency refers to sharing product-related information such as sourcing of raw materials, pricing, and terms (AMA, 2010; Epstein and Roy, 2003; Hofstede, 2003; Oh and Lucas, 2006; Samper and Schwartz, 2013; van Dijk, Duysters, and Beulens, 2003; WOMMA, 2010). In journalism, transparency refers to disclosing information about the conflicts of interest like when the writer worked with an interview subject in the past (Allen, 2008). In interpersonal communications and team dynamics, transparency includes sharing personal information such as one's feelings with others (Chaudoir and Fisher, 2010; Cozby, 1973; Jassawalla, Sashittal, and Malshe, 2010). In managing employees and within work teams, transparency includes sharing the motives, criteria, and reasons behind decisions, the absence of hidden agendas, as well as being open to giving and receiving feedback (Jassawalla, et al., 2010; Palanski, Kahai, and Yammarino, 2011; Vogelgesang and Lester, 2009). Finally, in public administration, transparency refers to sharing decision-making processes, analyses, and outcomes (Drew, et al., 2004; Sparrevik, Ellen, and Duijn, 2010). Thus, the information needed changes based on the stakeholder and the business context. The challenge is that it is up to each organization to determine its key stakeholder groups and the relevant information desired by each.

Unfortunately, these multiple representations of what "is" or "is not" relevant information to share within, across, and outside organizations creates space for ambiguity and opacity. Outlining and defining relevant information should be a key goal of industry organizations, individual firms, leaders, and employees. In concurrence with Dando and Swift's (2009) call for a universal standard for social, ethical, and environmental reporting, the transparency framework 
presented later is designed to foster the adoption of industry-wide and organizational-wide codes of conduct addressing the fundamental concepts of transparency.

Subsequent to determining what information is relevant, an organization has to determine how to present this information to stakeholders. Essentially, organizations must facilitate loweffort learning opportunities for stakeholders to increase perceptions of organization transparency. The level of organizational learning is positively related to perceived transparency of an organization (Srivastava and Frankwick, 2011). Uncertainty reduction is one common objective for business communication interactions (Daft and Lengel, 1986). It is important for organizations to recognize this and enable stakeholders to reduce their uncertainty about the organization or its products with minimal effort. A stakeholder may seek to reduce uncertainty by perusing an organization's website or directly communicating with the organization through email, instant chat, in person, or by phone and may seek information about not only favorable aspects of the product or firm, but also negative aspects of the product or firm. A stakeholder may want to know the weaknesses of a product, better understand how a product works or how it's made, the reasons behind a firm's profit or loss, the level expertise of its staff, or the firm's partnering companies. According to Uncertainty Reduction Theory (Berger and Calabrese 1975), individuals will increase information seeking behaviors as uncertainty increases. One way organizations can reduce information seeking behaviors and increase perceptions of transparency is by helping stakeholders with their goal to reduce uncertainty. The GRI suggests that organizations can do this by sharing information that is not only relevant but also complete, accurate, neutral, comparable, clear, timely, and in a format and language appropriate for the audience (GRI 2006; Bainbridge 2009). 
The literature also suggests that transparency perceptions can be facilitated by sharing information in a manner that yields learning opportunities requiring little effort. The information shared needs to be presented clearly (Christensen, 2002; Millar, Eldomiaty, Choi, and Hilton, 2005), completely (Piske, 2002), accurately (Millar, et al., 2005), timely (Beulens, et al., 2005;

Piske, 2002), in easy to access locations (Halachmi and Greiling, 2013; Santana and Wood, 2009; Sparrevik, et al., 2010; Zhou and Zhu, 2010), and in a format desired by those who want it (Beulens, et al., 2005). Millar et al. (2013) emphasize transparency "is the extent to which there is publicly available clear, accurate information, formal and informal" (p. 166). In conjunction, Beulens et al. (2013) suggest transparency is the "availability of the information necessary...at the right time and in the right way" (p. 484). Simply disclosing information is not enough to warrant perceptions of transparency with stakeholders. For instance, pharmaceutical companies are mandated to disclose certain information in their advertisements such as health risks. Habitually, the information is disclosed via "fine print," which is difficult to read and often goes unread by the very stakeholders who benefit from reading it. Consumers who come in contact with fine print communication strategies may not perceive this as completely transparent behavior due to the low accessibility and clarity of the disclosure method. Organizations should know their stakeholders well enough to understand what a "low effort" learning opportunity means. It is the organization's ethical responsibility, and simply a good business practice, to make it easy for stakeholders to reduce their uncertainty.

\subsection{The role of boundary spanners}

As mentioned above, boundary spanners play a crucial role in an organization's level of transparency. Some boundary spanners interact face-to-face with stakeholders, while others may generate communications that ultimately reach the stakeholders through various channels. It is 
imperative that organizations' executives serve as role models for transparency and clarify every boundary spanners' expectations relative to transparency. Without this clarity, individuals will be left to follow their own conscious and evolve into a transparency leader or barrier.

A second boundary spanner issue that executives must be cognizant of involves potentially different transparency "postures" held by boundary spanners within the same functional area (e.g., marketing, legal). If this pattern is allowed, then stakeholders will receive a mixed message from the organization.

A third issue involves potentially radically different transparency levels among an organization's different functional areas. For example, what if marketing is very transparent, but the production and/or financial areas are very opaque. Again, the organization should strive for a consistent level of transparency, as much as possible.

5.5 How does transparency relate to the perception vs. reality of ethical behavior?

The reality of ethical behavior (EBr) obviously relates to actual behaviors exhibited by organizational members. While $\mathrm{EBr}$ has a profound impact on stakeholder perceptions of ethical behavior (EBp), EBr and EBp are not always equal due to potential intervening variables. But, if both factors are high, as shown in Quadrant II in Figure 1, the organization simply needs to maintain its diligence in ensuring that both continue. However, if either factor is low, then the organization must do something different.

Insert Figure 1 about here

Quadrant I represents a situation in which the EBr is low, but EBp is high. Essentially, the stakeholders are being fooled by the organization's actions. Somehow, the organization is 
masking unethical behavior and stakeholders are not aware of it. This situation is not likely to endure. And, when stakeholders become aware of the reality, organizations can fall hard. The action step needed in Quadrant I involves addressing the poor ethical behaviors.

Quadrant III represents low EBr and EBp. The organization's ethical behavior is low and stakeholders know it. The action needed is to improve poor ethical behavior and make stakeholders aware of the improvement.

Quadrant IV represents high EBr, but low EBp. The organization actually has high ethical standards and behavior, but stakeholders perceive the organization as having poor ethical behavior. This is the classic situation in which increased transparency is needed.

\subsection{Transparency and ethical codes of conduct}

The critical need for greater transparency and its impact on perceptions of ethical conduct strongly imply that organizations should include transparency in their codes of conduct. Piercy and Lane (2007) propose that senior management should question all moral and ethical factors between business buyers and sellers. Business professionals employed at firms with ethical codes of conduct are significantly less accepting of questionable behavior toward most stakeholders (McKinney, Emerson, and Neubert, 2010). Dando and Swift (2003) argue that there is need for a universal standard for the provision of assurance of social, ethical and environmental reporting, and indeed for the credibility of the assurance providers themselves. Zappos.com, an online shoe and handbag retailer, represents Quadrant II above exceptionally well: it has made transparency a central part of the value proposition they offer to the marketplace, and the market has rewarded them for it. Zappos.com, operates with transparency as one of the company's 10 core family values. And the company acts on this core value. As just one example, on April 26, 2010, Zappos.com launched a live webcast of its internal “All 
Hands" quarterly employee meeting. The live broadcast included several hours of video to include pre-meeting, meeting, and happy hour activities. On the Zappos.com blog, an employee blogger wrote: "We invited the world to tune in live to our 'internal' meeting. For those who know the basics of how Zappos.com is run, you probably know that we're all about transparency so it only made sense to invite anyone and everyone to sit in on our largest meeting of the quarter” (Zappos.com, 2010). Zappos.com has been rewarded for its transparency: it was recognized in 2009, 2010 and 2011 by FORTUNE Magazine as one of the 100 Best Companies to Work For, was one of only 40 U.S. companies named a J.D. Power 2011 Customer Service Champion, and was valued at \$1.2B in 2009 when it was acquired by Amazon.com (in part for its best-in-class culture).

Like Zappos.com, firms who want to engage in responsible business practices should recognize calls by stakeholders for increased transparency as important: firms should incorporate transparency into their ethical codes of conduct as a value proposition they offer to the marketplace. Businesses should consider the below verbiage as a starting point for inclusion into their existing codes of conduct:

- We commit to providing transparency to our stakeholders by:

- Providing relevant information that is important to you in a timely manner, without delay, that is free from bias.

- Sharing not only the good stuff about our business, but also where we could use improvement.

- Affording you an opportunity to easily engage in open dialogue with us.

- Giving you an inside look into how we operate to include why we make the decisions that we do. 


\section{Proposed transparency framework}

A conceptual framework emerged from the data. It describes when transparency is especially important, what organizations can do to be more transparent, and the potential benefits of transparency (see Figure 2).

Insert Figure 2 about here

This framework is applicable at both the macro and micro-organizational levels. At the macro level, for example, executive leadership teams may find this framework useful as a starting point for developing transparency strategies. At the micro level, each department and boundary spanner can utilize this framework to help guide their transparency efforts with their particular stakeholders. The transparency framework suggests it is important for each department to not only know who its key stakeholders are, but also to clearly understand what information each stakeholder group needs and how they need it. This endeavor requires that transparency initiatives be grounded from the voice of the stakeholder, rather than the intuition of employees. Hence, some marketing and communication-related research may be required. Each department within the organization should ask its stakeholders the following questions:

- Are we currently providing you with the information you need? If not, what information do you need from us?

- What can we do differently to get you the information you need?

- How can we make it easy for you to get the information you need?

Salespeople, for example, can ask these questions to customers, human resources employees can ask these questions to the organization's employees, the executive leadership team can ask these 
questions to investors, and so on. Perceptions of transparency may increase simply by asking these questions. Of course, some stakeholders may want information that could never be shared, such as proprietary formulas and processes, or even strategy data that, if shared, could weaken the organization against the competition. It is important to communicate the reasons behind the organization's decision to keep this information private. It is possible that providing reasons for decisions not to share information may counteract any negative effects caused by withholding that information, so long as the reason communicated is agreeable to the stakeholder. For example, responding to stakeholder inquiries with, "it's just not our policy to share that information" lacks the reason behind withholding the information and would most likely cause decreased perceptions of an organization's transparency. This approach can lead to decreased trust, unfavorable attitudes toward the organization, and lowered purchase intentions. Consider more thoughtful responses that incorporate why the organization is unable to provide the information to curb such side effects.

\subsection{Develop a transparency scorecard}

With a little research, an organization should be able to develop a customized transparency scorecard, perhaps organized into the "dashboard indicator" format. The first step involves identifying all of the organization's key stakeholders, such as customers, government agencies (e.g., regulatory, legislative, tax-related), investors/stockholders, employees, suppliers, creditors, community/public, unions, media, activist groups, and business support groups. For each group chosen, a sampling of individuals in that stakeholder group could be surveyed utilizing a small set of questions (perhaps with a 5-point scale), such as: 
1. Overall, are you satisfied with the information available to you about our organization?

2. Are you satisfied with the extent that the information is easily and readily available?

3. Do you find the information you access easy to understand?

This kind of information should be easy to obtain and transform into a functional dashboard. Should any of the dashboard indicators hit the "red zone," then the organization should seek additional information for that particular stakeholder group. This research should seek answers to questions that involve what, why, when, where, how much, and so on.

\section{Conclusion}

The 21st century has been marked with numerous ethical lapses by businesses. Consequently, stakeholder confidence in an organization's abilities to operate within the constraints of social, ethical, and environmental standards has diminished (Hein, 2002; Hein, 2002). The mounting calls by stakeholders to improve the ethical decision making of businesses have led to the rise of research in transparency within the last decade. As evidence of this trend, zero papers in the sample were published prior to 2002. To date, the majority of research on transparency is conceptual or qualitative with a limited number of quantitative studies. Scholars are still attempting to conceptually define and measure transparency, which could be one reason why this body of literature has not made strides in quantitatively understanding transparency's antecedents and consequences.

This systematic literature review is the first review and synthesis of peer reviewed journals exploring transparency in organizational contexts. In alignment with the subject of this paper, a rigorous methodology was done in a systematic, transparent, and reproducible manner. The effort to discover how transparency is defined revealed that one prominent void in this burgeoning field was the lack of a definition of the fundamental construct of transparency. A 
quality definition classification was therefore developed and applied in order to evaluate transparency definitions identified in the sample and provide a guide for content analysis. Thus, this study also contributes to the methodology of evaluating construct definitions to advance empirical research. The findings illustrate that not only is there a lack of a concise definition of transparency but also that these definitions are either not applicable organizational wide or not representative of the central theme of "openness" found in the sample. Based upon this process and using the classification as a guide, transparency is defined as the extent to which a stakeholder perceives an organization provides learning opportunities about itself. This definition provides a conceptual foundation from which both academics and practitioners can advance transparency theory and empirically explore its application.

Next, this review explored the antecedents and consequences of transparency. This process led to the development of a transparency framework (Figure 1) which supports the growing notion that transparency can improve the social, ethical, and environmental practices of organizations. The proposed model describes when transparency is especially important, what organizations can do to be more transparent, and the potential benefits of transparency. The transparency framework can be used as a guide for organizations attempting to change their behavior, image, and performance by adopting transparency as value in their organization. At its core, transparency means that a firm is open with stakeholders, granting access to, at a minimum, information that allows stakeholders to better understand the company, its products, and reasons for certain actions and decisions. In addition, the framework can be used to create and adopt a universal (i.e., industry-wide or even societal-wide) code of conduct. Furthermore, this review, definition, and framework provide a template for academics to advance transparency theory, and empirically test the construct's application. 
Lastly, this review sheds light on the favorable impacts of transparency. The findings indicate that benefits are gained by organizations as well as its employees, customers and partners, and society when transparency is present. If companies are seeking to improve their triple bottom line, their ethical decision making, and their competitive advantage this review demonstrates it would be wise for them to facilitate the adoption of transparency within their organization and their industry. Stakeholders and the challenges of the 21 st century have created a demand for transparency sparking the development of this new field, and the need for continued discussion.

It is proposed that organizations which make a conscious proactive decision to be transparent will be rewarded by its stakeholders for such ethical behavior; and conversely, financial institutions, governments, and businesses that do not listen to the call for increased transparency will be punished by its stakeholders to include further increased skepticism and lack of trust, and ultimately the sale going to the most transparent competitor. 


\section{References}

Ahearne, M., Jelinek, R., and Jones, E. (2007), "Examining the effect of salesperson service behavior in a competitive context", Journal of the Academy of Marketing Science, 35(4), 603-616.

Allen, D. (2008), "The trouble with transparency”, Journalism Studies, 9(3), 323-340.

AMA. (2010), "Statement of ethics", available at: http://www.marketingpower.com/AboutAMA/Pages/Statement\%20of\%20Ethics.aspx?s $=$ transparency (accessed 11 February 2010).

Arens, L., Deimel, M., and Theuvsen, L. (2011), “Transparency in meat production: consumer perceptions at the point of sale", Journal of Agricultural Science and Technology B, 1(8), 40-51.

Ashley, C., and Leonard, H. (2009), "Betrayed by the buzz? Covert content and consumer-brand relationships", Journal of Public Policy and Marketing, 28(2), 212-220.

Awaysheh, A., and Klassen, R. D. (2010), “The impact of supply chain structure on the use of supplier socially responsible practices", International Journal of Operations and Production Management, 30(12), 1246-1268.

Baba, V. V., and HakemZadeh, F. (2012), "Toward a theory of evidence based decision making', Management decision, 50(5), 832-867.

Baker, S. (2008), "The model of the principled advocate and the pathological partisan: A virtue ethics construct of opposing archetypes of public relations and advertising practitioners", Journal of Mass Media Ethics, 23, 235-253. 
Bansal, P., and Kistruck, G. (2006), "Seeing is (not) believing: Managing the impressions of the firm's commitment to the natural environment", Journal of Business Ethics, 67(2), 165 180.

Bennis, W., Goleman, D., O'Toole, J., and Biederman, P. W. (2008), Transparency: how leaders create a culture of candor. San Francisco, CA US: Jossey-Bass.

Bernstein, D. (2009), "Rhetoric and reputation: some thoughts on corporate dissonance", Management Decision, 47(4), 603-615.

Bessire, D. (2005), “Transparency: a two-way mirror?” International Journal of Social Economics, 32(5), 424-438.

Beulens, A. J., Broens, D.-F., Folstar, P., and Hofstede, G. J. (2005), "Food safety and transparency in food chains and networks: Relationships and challenges", Food Control, $16(6), 481-486$.

Bhaduri, G., and Ha-Brookshire, J. E. (2011), "Do transparent business practices pay? Exploration of transparency and consumer purchase intention," Clothing and Textiles Research Journal, 29(2), 135-149.

Bird, J., and Wang, C. (2011), “Authentic leadership and budget-building practices: Superintendents reveal origins, strategies, and connections", Academy of Educational Leadership Journal, 15(3), 143-160.

Blomgren, M., and Sundén, E. (2008), “Constructing a European healthcare market: The private healthcare company Capio and the strategic aspect of the drive for transparency," Social Science and Medicine, 67(10), 1512-1520.

Brown, N., and Michael, M. (2002), "From authority to authenticity: the changing governance of biotechnology", Health, Risk and Society, 4(3), 259-272. 
Campbell, J. L. (2007), "Why would corporations behave in socially responsible ways? An institutional theory of corporate social responsibility," Academy of Management Review, $32(3), 946-967$.

Carter, R. E., and Curry, D. J. (2010), “Transparent pricing: theory, tests, and implications for marketing practice", Journal of the Academy of Marketing Science, 38(6), 759-774.

Chaudoir, S., and Fisher, J. (2010), “The disclosure processes model: Understanding disclosure decision making and post disclosure outcomes among people living with a concealable stigmatized identity", Psychological Bulletin, 136(2), 236-256.

Cheng, J. Y. (2011), “Power, transparency and control: Hong Kong people’s adaptations to life", International Journal for the Semiotics of Law-Revue internationale de Sémiotique juridique, 24(2), 163-177.

Christensen, L. (2002), “Corporate communication: The challenge of transparency”, Corporate Communications: An International Journal, 7(3), 162-168.

Chua, A., Robertson, K., Parackal, M., and Deans, K. R. (2012), “Conveying trust: Transparency and credibility methods in corporate blogs", New Zealand Journal of Applied Business Research, 10(2), 1-15.

Cornand, C., and Heinemann, F. (2008), “Optimal degree of public information dissemination”, The Economic Journal, 118(528), 718-742.

Cowley, E., and Barron, C. (2008), "When product placement goes wrong: The effects of program liking and placement prominence", Journal of Advertising, 37(1), 89-98.

Cozby, P. (1973), “Self-Disclosure: A literature review," Psychological Bulletin, 79(2), 73-91.

Cutler, C. (2008), "Exxon Valdez Oil Spill”, available at: http://www.eoearth.org/article/Exxon Valdez oil spill (accessed 13 April 2010). 
Dando, N., \& Swift, T. (2003), “Transparency and assurance: Minding the credibility gap", Journal of Business Ethics, 44(2), 195-200.

Darke, P., and Ritchie, R. (2007), “The defensive consumer: Advertising deception, defensive processing, and distrust", Journal of Marketing Research, 44(1), 114-127.

das Neves, J. C., and Vaccaro, A. (2013), “Corporate transparency: A perspective from Thomas Aquinas' summa theologiae", Journal of Business Ethics, 1-10.

DeKinder, J., and Kohli, A. (2008), "Flow signals: How patterns over time affect the acceptance of start-up firms", Journal of Marketing, 72(5), 84-97.

Doorey, D. J. (2011), “The transparent supply chain: From resistance to implementation at Nike and Levi-Strauss", Journal of Business Ethics, 103(4), 587-603.

Drew, C. H., Nyerges, T. L., and Leschine, T. M. (2004), "Promoting transparency of long-term environmental decisions: The Hanford Decision Mapping System Pilot Project”, Risk Analysis, 24(6), 1641-1664.

Eggert, A., and Helm, S. (2003), "Exploring the impact of relationship transparency on business relationships: A cross-sectional study among purchasing managers in Germany", Industrial Marketing Management, 32(2), 101-108.

Eisingerich, A., and Bell, S. (2008), "Perceived service quality and customer trust: Does enhancing customers' service knowledge matter?” Journal of Service Research, 10(3), 256.

Elkington, J. (1998), "Partnerships from cannibals with forks: The triple bottom line of $21^{\text {st }}$ century business", Environmental Quality Management, 8(1), 37-51.

Elkington, J. (2004), Enter the triple bottom line, The triple bottom line: Does it all add up, 1-16. 
Epstein, M. J., and Roy, M.-J. (2003), “Improving sustainability performance: specifying, implementing and measuring key principles”, Journal of General Management, 29(1), 15 31.

Ferrell, O., and Gresham, L. (1985), “A contingency framework for understanding ethical decision making in marketing", The Journal of Marketing, 49(3), 87-96.

Friestad, M., and Wright, P. (1994), “The persuasion knowledge model: How people cope with persuasion attempts", Journal of Consumer Research, 21(1), 1-31.

Frynas, J. G. (2010), “Corporate social responsibility and societal governance: Lessons from transparency in the oil and gas sector”, Journal of Business Ethics, 93(2), 163-179.

Garrard, J. (1999), Health sciences literature review made easy: the matrix method (1st ed. ed.): Jones and Bartlett Learning.

Granados, N., and Gupta, A. (2013), “Transparency strategy: Competing with information in a digital world", MIS quarterly, 37(2), 637-641.

GRI. (2006). Sustainability reporting guidelines (PDF): GRI.

Gupta, S., Grant, S., and Melewar, T. C. (2008), “The expanding role of intangible assets of the brand", Management Decision, 46(6), 948-960.

Halachmi, A., and Greiling, D. (2013), “Transparency, e-Government, and accountability”, Public Performance and Management Review, 36(4), 572-584.

Halter, M. V., and de Arruda, M. C. C. (2009), "Inverting the pyramid of values? Trends in less developed countries", Journal of Business Ethics, 90(3), 267-275.

Halter, M. V., de Arruda, M. C. C., and Halter, R. B. (2009), “Transparency to reduce corruption?” Journal of Business Ethics, 84(3), 373-385. 
Hein, K. (2002, July 1), “As big scandals mount, experts say be truthful--and careful” In Ads. Brandweek, July 1.

Hofstede, G. (2003, July 5-9), “Transparency in netchains”, Paper presented at the EFITA, Debrecen, Hungary.

Holusha, J. (1989), “Exxon's public-relations problem”, available at: http://www.nytimes.com/1989/04/21/business/exxon-s-public-relations-problem.html (accessed 12 April 2010).

Hood, C. (2007), “What happens when transparency meets blame-avoidance?” Public Management Review, 9(2), 191-210.

Hultman, J., and Axelsson, B. (2007), "Towards a typology of transparency for marketing management research”, Industrial Marketing Management, 36(5), 627-635.

Hunt, S., and Vitell, S. (2006), "The general theory of marketing ethics: A revision and three questions", Journal of macromarketing, 26(2), 143.

Jahansoozi, J. (2006), “Organization-stakeholder relationships: exploring trust andtransparency”, Journal of Management Development, 25(10), 942-955.

Jassawalla, A. R., Sashittal, H. C., and Malshe, A. (2010), "Effects of transparency and at stakeness on students' perceptions of their ability to work collaboratively in effective classroom teams: A partial test of the Jassawalla and Sashittal model”, Decision Sciences Journal of Innovative Education, 8(1), 35-53.

Kaikati, A., and Kaikati, J. (2004), "Stealth marketing: How to reach consumers surreptitiously", California Management Review, 46(4), 6-22.

Klara, R. (2010, May 10, 2010), "When the oil spill is this big, it pays not to be crude", Brandweek, 51, 1. 
Klassen, T. P., Jadad, A. R., and Moher, D. (1998), “Guides for reading and interpreting systematic reviews: I. Getting started", Archives of Pediatrics and Adolescent Medicine, 152(7), 700-704.

Lazarus, H., and McManus, T. (2006), “Transparency guru: An interview with Tom McManus”, Journal of Management Development, 25(10), 923-936.

MacKenzie, S. (2003), “The dangers of poor construct conceptualization”, Journal of the Academy of Marketing Science, 31(3), 323-326.

Makary, M. (2012), "How to stop hospitals from killing us”, Wall Street Journal Eastern Edition, 259(69), C1-C2.

Mayer, R. C., Davis, J. H., \& Schoorman, F. D. (1995), “An integrative model of organizational trust", Academy of Management Review, 20,709-734.

McKay, L. (2008), “Transparency”, Customer Relationship Management, December 2008, 24 29.

McKinney, J. A., Emerson, T. L., and Neubert, M. J. (2010), “The effects of ethical codes on ethical perceptions of actions toward stakeholders", Journal of Business Ethics, 97(4), $505-516$.

Miao, L., and Mattila, A. S. (2007), "How and how much to reveal? The effects of price transparency on consumers' price perceptions", Journal of Hospitality and Tourism Research, 31(4), 530-545.

Millar, C. C., Eldomiaty, T. I., Choi, C. J., and Hilton, B. (2005), “Corporate governance and institutional transparency in emerging markets", Journal of Business Ethics, 59(1-2), 163 174. 
Misangyi, V. F., Weaver, G. R., and Elms, H. (2008), “Ending corruption: The interplay among institutional logics, resources, and institutional entrepreneur",. Academy of Management Review, 33(3), 750-770.

Nielsen, C. (2004), "Business reporting: How transparency becomes a justification mechanism" Aarhus School of Business, Department of Accounting, Finance and Logistics, Management Accounting Research Group.

Nielsen, C. (2005), "Modelling transparency: A research note on accepting a new paradigm in business reporting", Aarhus School of Business, Department of Accounting, Finance and Logistics, Management Accounting Research Group.

O'Malley, P., Rainford, J., and Thompson, A. (2009), “Transparency during public health emergencies: from rhetoric to reality", Bulletin of the World Health Organization (87), 614-618.

Oh, W., and Lucas, H. C. (2006), "Information technology and pricing decisions: price adjustments in online computer markets", MIS quarterly, 30(3), 755-775.

Palanski, M. E., Kahai, S. S., and Yammarino, F. J. (2011), "Team virtues and performance: An examination of transparency, behavioral integrity, and trust”, Journal of Business Ethics, 99(2), 201-216.

Parris, D., and Welty Peachey, J. (2013), “A systematic literature review of servant leadership theory in organizational contexts," Journal of Business Ethics, 113(3), 377-393.

Piercy, N. F., \& Lane, N. (2007), "Ethical and moral dilemmas associated with strategic relationships between business-to-business buyers and sellers," Journal of Business Ethics, 72(1), 87-102. 
Pirson, M., and Malhotra, D. (2008), "Unconventional insights for managing stakeholder trust”, MIT Sloan Management Review, 49, 43-50.

Piske, R. (2002), “German acquisitions in Poland: an empirical study on integration management and integration success", Human Resource Development International, 5(3), 295-312.

Reidenbach, R., and Robin, D. (1990), “Toward the development of a multidimensional scale for improving evaluations of business ethics”, Journal of Business Ethics, 9(8), 639-653.

Reidenbach, R., Robin, D., and Dawson, L. (1991), “An application and extension of a multidimensional ethics scale to selected marketing practices and marketing groups", Journal of the Academy of Marketing Science, 19(2), 83-92.

Robin, D., and Reidenbach, R. (1987), “Social responsibility, ethics, and marketing strategy: Closing the gap between concept and application", The Journal of Marketing, 51(1), 44 58.

Roloff, J., and Aßländer, M. S. (2010), "Corporate autonomy and buyer-supplier relationships: The case of unsafe Mattel toys", Journal of Business Ethics, 97(4), 517-534.

Ross, J. S., Gross, C. P., and Krumholz, H. M. (2012), "Promoting transparency in pharmaceutical industry-sponsored research", Journal Information, 102(1).

Rust, R., and Cooil, B. (1994), "Reliability measures for qualitative data: Theory and implications", Journal of Marketing Research, 1-14.

Samper, A., and Schwartz, J. A. (2013), "Price inferences for sacred versus secular goods:

Changing the price of medicine influences perceived health risk", Journal of Consumer Research, 39(6), 1343-1358.

Santana, A., and Wood, D. (2009), “Transparency and social responsibility issues for Wikipedia”, Ethics and Information Technology, 11, 133-144. 
Schoorman, F. D., Mayer, R.C., and Davis, J.H. (2007), “An Integrative Model of Organizational Trust: Past, Present, and Future”, Academy of Management Review, 32 (2), 344-354.

Sparrevik, M., Ellen, G. J., and Duijn, M. (2010), "Evaluation of factors affecting stakeholder risk perception of contaminated sediment disposal in Oslo Harbor”, Environmental science and technology, 45(1), 118-124.

Srivastava, P., and Frankwick, G. L. (2011), “Environment, management attitude, and organizational learning in alliances", Management decision, 49(1), 156-166.

Stanley, D. J., Meyer, J. P., and Topolnytsky, L. (2005), “Employee cynicism and resistance to organizational change", Journal of Business and Psychology, 19(4), 429-459.

Stasavage, D. (2004), “Open-door or closed-door? Transparency in domestic and international bargaining", International Organization, 58(04), 667-703.

Street, C. T., and Meister, D. B. (2004), "Small business growth and internal transparency: the role of information systems", MIS quarterly, 28(3), 473-506.

Tapscott, D., and Ticoll, D. (2003), “The naked corporation: how the age of transparency will revolutionize business", Don Tapscott and David Ticoll: New York: Free Press, c2003.

Tenbrunsel, A.E., and Smith-Crowe, K. (2008), "Ethical decision-making: where we've been and where we're going”, Academy of Management Journal, 2(1), 545-607).

Urban, G., Amyx, C., and Lorenzon, A. (2009), “Online trust: State of the art, new frontiers, and research potential", Journal of Interactive Marketing, 23, 179-190.

Vaccaro, A. (2012), "To pay or not to pay? Dynamic transparency and the fight against the mafia'sextortionists", Journal of Business Ethics, 106(1), 23-35.

Vaccaro, A., and Sison, A. J. G. (2011), “Transparency in business: The perspective of catholic social teaching and the "Caritas in Veritate"”, Journal of Business Ethics, 100(1), 17-27. 
van Dijk, S., Duysters, G., and Beulens, A. (2003), “Transparency dilemmas in strategic alliances”, Position Paper KLICT, Eindhoven University of Technology.

Vogelgesang, G. R., and Lester, P. B. (2009), “Transparency: How leaders can get results by laying it on the line", Organizational Dynamics, 38(4), 252-260.

Warren, H. B., Burns, D. J., and Tackett, J. (2012), “The likelihood of deception in marketing: A criminological contextualization”, Business and Professional Ethics Journal, 31(1), 107.

Weed, M. (2005), “"Meta Interpretation": A method for the interpretive synthesis of qualitative research”, Forum Qualitative Sozialforschung/ Forum: Qualitative Social Research, 6(1), $1-17$.

Wei, M., Fischer, E., and Main, K. (2008), “An examination of the effects of activating persuasion knowledge on consumer response to brands engaging in covert marketing”, Journal of Public Policy and Marketing, 27(1), 34-44.

WOMMA. (2010), "Ethics code", available at: http://womma.org/ethics/faqs/ (accessed 16 February 2010).

Yim, C., Tse, D., and Chan, K. (2008), "Strengthening customer loyalty through intimacy and passion: Roles of customer-firm affection and customer-staff relationships in services", Journal of Marketing Research, 45(6), 741-756.

Zhou, Z. Z., and Zhu, K. X. (2010), “The effects of information transparency on suppliers, manufacturers, and consumers in online markets", Marketing Science, 29(6), 1125-1137. 
Table 1

Quality Definition Evaluation Criteria

\begin{tabular}{|c|c|c|}
\hline Criteria & Criteria Explanation & Definition Evaluation \\
\hline $\begin{array}{l}\text { Object of } \\
\text { Measurement } \\
\text { Specificity }\end{array}$ & $\begin{array}{l}\text { Definition explicitly states the } \\
\text { focal object for the construct } \\
\text { (i.e. what is being measured). }\end{array}$ & $\begin{array}{l}\text { This definition meets the criterion of } \\
\text { object of measurement specificity. What } \\
\text { is being measured is the extent of } \\
\text { perceived learning opportunities provided } \\
\text { by an organization. }\end{array}$ \\
\hline $\begin{array}{l}\text { Object Attribute } \\
\text { Specificity }\end{array}$ & $\begin{array}{l}\text { Definition includes whether } \\
\text { construct is a : thought } \\
\text { (cognition, value, intention, } \\
\text { subjective norm), feeling } \\
\text { (attitude, emotion), perception, } \\
\text { action (behavior, activity), } \\
\text { outcome, or intrinsic } \\
\text { characteristic (e.g. cognitive } \\
\text { ability, structure, speed, } \\
\text { conscientiousness) }\end{array}$ & $\begin{array}{l}\text { This definition meets the criterion of } \\
\text { object attribute specificity. That which is } \\
\text { being measured is a perception. This } \\
\text { clearly distinguishes transparency as } \\
\text { being measured from the stakeholder's } \\
\text { point of view, rather than from the } \\
\text { organization's point of view. }\end{array}$ \\
\hline Entity Specificity & $\begin{array}{l}\text { Definition includes the object } \\
\text { to which property applies (a } \\
\text { person, relationship, dyad, } \\
\text { group/team, network, } \\
\text { organization) }\end{array}$ & $\begin{array}{l}\text { This definition meets the criterion of } \\
\text { entity specificity. The object to which the } \\
\text { property applies is an organization. The } \\
\text { organization is the entity that is being } \\
\text { evaluated. Depending on the context in } \\
\text { which transparency is measured, } \\
\text { "organization" could also refer to specific } \\
\text { departments. }\end{array}$ \\
\hline $\begin{array}{l}\text { Conceptualization } \\
\text { Precision }\end{array}$ & $\begin{array}{l}\text { Construct is not defined in } \\
\text { terms of examples as } \\
\text { evidenced by words such as } \\
\text { "related to", "similar to", } \\
\text { "includes", "involves", or } \\
\text { "described as"; construct is not } \\
\text { defined in terms of its } \\
\text { antecedents or consequences } \\
\text { as evidenced by words such as } \\
\text { "result of", "cause of", etc. } \\
\text { indicating a causal relationship } \\
\text { between it and another } \\
\text { construct; and construct is } \\
\text { defined in terms of what it is } \\
\text { rather than what it is not. }\end{array}$ & $\begin{array}{l}\text { This definition meets the criterion of } \\
\text { conceptualization precision as it is not } \\
\text { defined in terms of antecedents or } \\
\text { consequences. It is suggest that two key } \\
\text { antecedents of transparency include: } \\
\text { sharing relevant information and enabling } \\
\text { low-effort (easy) learning opportunities. } \\
\text { Numerous consequences of transparency } \\
\text { suggested in the literature are cited. None } \\
\text { of the antecedents or consequences is } \\
\text { mentioned in this transparency definition. }\end{array}$ \\
\hline $\begin{array}{l}\text { Overall construct } \\
\text { clarity }\end{array}$ & $\begin{array}{l}\text { Definition is written } \\
\text { parsimoniously with clear, } \\
\text { unambiguous terms. }\end{array}$ & $\begin{array}{l}\text { This definition meets the criterion of } \\
\text { overall construct clarity. An } \\
\text { organization's "learning opportunities" } \\
\text { includes anything it does or provides to } \\
\text { facilitate stakeholder learning. }\end{array}$ \\
\hline
\end{tabular}


Figure 1

Perception and Reality of Ethical Behavior Grid

Very high

Perception of

Ethical

Behavior

Very low

\begin{tabular}{|l|l|}
\hline $\begin{array}{l}\text { QUADRANT I } \\
\text { High perception }+ \\
\text { Low reality }\end{array}$ & $\begin{array}{l}\text { QUADRANT II } \\
\text { High perception }+ \\
\text { High reality }\end{array}$ \\
$\begin{array}{l}\text { Stakeholders are being } \\
\text { fooled - condition not } \\
\text { likely to endure- } \\
\text { actual behavior must } \\
\text { change }\end{array}$ & $\begin{array}{l}\text { efforts to maintain } \\
\text { needed }\end{array}$ \\
\hline $\begin{array}{l}\text { QUADRANT III } \\
\text { Low perception }+ \\
\text { Low reality }\end{array}$ & $\begin{array}{l}\text { QUADRANT IV } \\
\text { Low perception }\end{array}$ \\
$\begin{array}{l}\text { Stakeholder } \\
\text { perceptions accurate- } \\
\text { major efforts need to } \\
\text { change behavior and } \\
\text { communicate the new } \\
\text { behavior }\end{array}$ & $\begin{array}{l}\text { Likely a low level of } \\
\text { transparency exists } \\
\text {-greater efforts to } \\
\text { achieve } \\
\text { transparency } \\
\text { needed }\end{array}$ \\
\hline $\begin{array}{l}\text { Very low } \\
\text { Very high }\end{array}$
\end{tabular}

Reality of Ethical Behavior 
Conditions when Transparency is Strongly Suggested

\section{Increase Transparency Efforts When:}

- Stakeholders distrust you

- The industry you're in (and/or your brand) has an unfavorable reputation

- Managing public negativity toward your brand (and especially during public scandals)

- You sell undifferentiated products/services

- You strive for ethical excellence

\section{How to Increase Transparency}

\section{Share relevant information. Make it easy for}

What information do your

stakeholders need to make

informed decisions?

Suggestions include:

- Product information, both pros and cons

- Motives and reasons behind decisions

- Organizational short and long-term objectives and goals

- Raw data from which summaries and decisions have been made

- Conflicts of interest

- Primary and secondary data Information sources

- Supply chain and materials sourcing

- Triple bottom line metrics stakeholders to learn. How do your stakeholders want to receive information?

Share information that is:

- Clearly understood, and easy to interpret

- Free from jargon

- Parsimoniously complete

- Accurate

- Time-sensitive

- Easily accessible

- In a desired format

- Unbiased

- Comparable to other sources

- Not "fine print"

- At a desired time and place with advance notice (for face-to-face knowledge dissemination to groups)

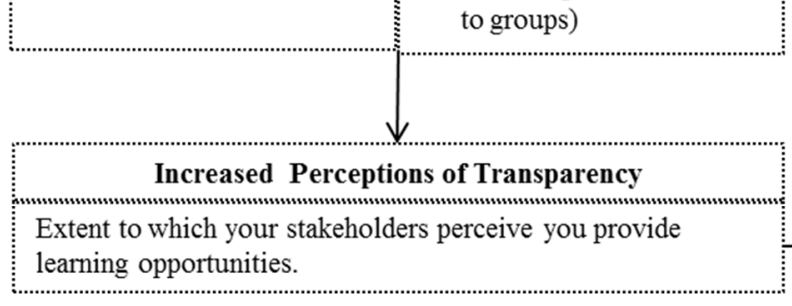

Figure 2

Proposed Transparency Framework

Employee Benefits

- (+) Job-role engagement

- (+) Understanding of job-role relation to organizational goals

- (+) Job performance

- (+) Trust in management

- (+) Decision-making in accordance with organization goals and high ethical standards

- $(+)$ Cooperation during acquisitions and mergers

- (-) Opportunistic behaviors

\section{Customer Benefits}

- $(+)$ Favorable attitudes toward brand

- $(+)$ Perceived firm credibility

- (+) Perceived price fairness

- (+) Perceived fairness in firm processes and procedures

- (+) Customer satisfaction

- (+) Perceived value of firm's products

- (+) Trust in organization

- (+) Purchase intention

Supply Chain Benefits

- (+) Supply chain efficiencies (i.e. flow of materials)

- (+) Member cooperation

- (+) Trust

Organizational Benefits

- (+) Competitive advantage of differentiation of product offerings

- (+) Organizational-wide understanding of the competition

- (+) Collaboration and cooperation with stakeholders

- (+) Commitment to stakeholders/healthy stakeholder relationships

- (+) Business practices that are more ethically sound and socially responsible

- (-) Haphazard decision-making

- (+) Favorable brand image

- (+) Marketing message persuasiveness

- (+) Sales and profit margin

Societal Benefits

- $(+)$ Educated consumers

- (+) Equitable balance of power between organizations and stakeholders (consumers, citizens, investors, etc.)

- (-) Exploitation of societal resources

- (+) Reality presented and seen "as is" rather than skewed in favor of beneficiaries

(-) Hidden agendas and secrets

- (-) Corruption and deception

- (+) Ability for stakeholders to verify behaviors and hold organizations accountable 